\title{
КАЧЕСТВО ПРАВОВОГО ОПОСРЕДОВАНИЯ ОТНОШЕНИЙ НАЙМА ТРУДА В РОССИИ В КОНЦЕ ХІХ ВЕКА
}

\begin{abstract}
Аннотация: В статье говорится о том, что основным мотивом развития качества российского законодательства о найме труда в конце ХІХ века явилась необходимость устранения массовых волнений среди рабочего населения, находящегося в состоянии крайне жестокой эксплуатации на капиталистических фабриках. Направление, по которому шло развитие качества законодательства о фабричном труде, было предсказуемым - это, прежде всего, введение ограничений на использование детского и женского труда, а также формирование системь государственного надзора за исполнением данных правоустановлений. Кроме того, путем введения соответствуюших императивных норм предполагалось ограничить самостоятельность хозяев фабричньх заведений при юридическом оформлении условий взаимоотношений сторон. Как результат, поставленнье перед государством задачи обеспечить порядок на предприятиях и одновременно устранить наиболее явные проявления эксплуатацчии труда оказали значительное воздействие на последующее развитие качества законодательства о труде. В итоге мы можем говорить не только о появлении самостоятельного предмета и метода трудового права, но и об образовании системы отрасли трудового права в изелом.
\end{abstract}

Ключевые слова: Договор, качество правового регулирования, конец ХІХ века, личный найм, наемный работник, наниматель, нормативный правовой акт, труд, трудовые отношения, фабричное законодательство.

Abstract: The author states that the main motive for improving the quality of the Russian legislation on employment at the end of the $19^{\text {th }}$ century became the necessity to alleviate the mass unrest among the working class, who were severely exploited at the capitalist factories. The predictable course of improvement of quality of the legislation on factory labor included first and foremost the implementation of restrictions on child and female labor, as well as forming of the system of government oversight that would ensure the adherence to these policies. In addition to that, implementation of the corresponding imperative norms was supposed to limit the autonomy of the factory owners in the legal arrangement of the employer-employee relations. As a result, the tasks set before the government to ensure the discipline in the enterprises and simultaneously prevent the most evident cases of labor exploitation, have positively affected the future development of the quality of labor legislation.

Keywords: Contract, quality of legal regulation, late $19^{\text {th }}$ century, private employment, hired labor, employer, normative legal act, work, work relations, labor legislation.

1880-1881 гг. на промышленных предприятиях в производство внедрялись механизированные системы, в связи с чем произошло снижение спроса на рабочие руки, и еще более ухудшилось положение трудящихся. Начиная с этого периода, протесты и выступления рабочих приобретают массовый характер. Как отмечает И.Ю. Ташбекова, целый ряд забастовок среди рабочих был вызван постоянно ухудшающимися условиями труда - антисанитарными условиями работы в рабочих помещениях, отсутствием нормативно закрепленной продолжительности рабочего времени, тарификации и контролирования выплат заработной платы ${ }^{1}$.

${ }^{1}$ Ташбекова И.Ю. Государственное регулирование труда несовершеннолетних и женщин России в конце XIX века
Это явилось причиной существенной корректировки качества правового регулирования взаимоотношений рабочих и фабрикантов.

Однако кризисные явления в экономике и спад промышленного производства, в свою очередь, некоторое время способствовали отказу от ночных работ и ограничению продолжительности рабочего времени, что привело, в конечном счете, к введению соответствующих узаконений и качественному росту фабричного законодательства.

Нами не отрицается и того, что принятию первых фабричных законов в России и, соответственно, пере-

// Черные дыры в российском законодательстве. 2008. № 3. C. 269. 
ходу трудового законодательства на новый, качественный, путь развития способствовала во многом инициатива Н.Х. Бунге, министра финансов в 1881-1886 гг. ${ }^{2}$ Вышеизложенное позволяет констатировать, что все эти факторы стимулировали деятельность государства по развитию качества трудовых установлений.

Стоит отметить, что в связи с отсутствием адекватных правовых средств, способных вольнонаемный труд регулировать, пришло осознание того, что требуется обособленное фабричное законодательство, направленное на законодательное урегулирование отношений между нанимателями и наемными работниками. Вследствие этого требовалось в целом качественно переработать законодательство, регулирующее труд наемных работников. В частности, реформирование качества трудового законодательства требовало принятия единого нормативного правового акта о труде, который содержал бы общие положения о договоре личного найма безотносительно сферы его применения, а также служил бы основой для последующей регламентации особенностей труда по найму отдельных категорий работников. Поскольку жесткие формы эксплуатации труда касались всех рабочих без исключения и, следовательно, как такового государственного регулирования труда отдельных категорий лиц в стране не существовало, стала очевидной также необходимость качественно урегулировать порядок применения труда по найму таких категорий работников, как женщин и детей.

В частности, в 1882 г. был принят Закон «О малолетних, работающих на заводах, фабриках и мануфактурах» ${ }^{3}$, постановивший, что дети, не достигшие 12 лет от роду, к работам не допускаются. Рабочий день подростков 12-15 лет в промышленных заведениях ограничивался 8 часами в сутки, не включая времени, необходимого на завтрак, обед, ужин, посещение школы и на отдых. Притом их работа не должна была продолжаться более 4-х часов подряд. Привлечение подростков 12-15 лет к работе в ночное время (между 9-ю часами вечера и 5-ю часами утра), в воскресенье и праздничные дни запрещалось. Малолетних, не имеющих 15 лет, воспрещалось допускать к работам, которые по своим характеристикам являлись вредными для их здоровья или изнурительными. Владельцы предприятий должны были предоставлять возможность детям посещать шко-

\footnotetext{
${ }^{2}$ См.: Валетов Т.Я. Фабричное законодательство в России до Октябрьской революции. URL: http://www.hist.msu.ru (дата обращения: 29.07.2013).

${ }^{3}$ Высочайше утвержденное мнение Государственного Совета «О малолетних, работающих на заводах, фабриках и мануфактурах»
} от 1 июня 1882 года. ПСЗ. III. Т. 2. № 931. лу не менее 3 часов ежедневно или 18 часов в неделю (ст. 1). Для надзора за исполнением постановлений о труде и обучении малолетних рабочих предусматривалось учреждение особой инспекции (ст. 2), которая и стала позднее фабричной инспекцией. Однако надлежащее качество положений Закона не было достигнуто в связи с тем, что отсутствовала ясность относительно сферы его действия, а также потому, что еще некоторое время по разрешению министра финансов допускалась в случае надобности работа детей от 10 лет и ночная работа (не более 4-х часов в сутки) детей 12-15 лет (ст. 6). И лишь в 1884 г. государственное нормирование детского труда стало выгодно отличаться по своему качеству, поскольку Законом «О взысканиях за нарушения постановлений о работе малолетних на заводах, фабриках, мануфактурах и в ремесленных заведениях» ${ }^{4}$ были введены соответствующие организационно-правовые механизмы, обеспечивающие исполнение этих трудовых норм. Так, во исполнение норм о работе малолетних предусматривалась ответственность (арест не свыше одного месяца или денежное взыскание не свыше ста рублей) владельцев или управляющих промышленных учреждений и заведений за виновное неисполнение правил относительно работы малолетних (ст.ст. 1 и 2).

С 1 октября 1885 г. на ткацком производстве в виде опыта на три года воспрещаются ночные работы для женщин и подростков, не достигших 17-ти лет. Министр финансов по согласованию с министром внутренних дел мог распространять эту меру и на другие промышленные заведения (ст. 1) 5 . Мы можем в связи с этим заметить, что в указанном Законе впервые находит законодательное закрепление специальное правило о работе женщин. Однако иные нормы для регулирования женского труда в то время отсутствовали, и женщинам приходилось работать в неблагоприятных условиях вплоть до самых родов. При этом женщины, работая наравне с мужчинами, получали меньшую плату за свой труд ${ }^{6}$. Сказанное позволяет судить о крайне низком качестве проводимых реформ в области законодательного регулирования труда женщин.

\footnotetext{
${ }^{4}$ Высочайше утвержденное мнение Государственного Совета «О взысканиях за нарушения постановлений о работе малолетних на заводах, фабриках, мануфактурах и в ремесленных заведениях» от 5 июня 1884 года. ПСЗ. ІІІ. Т. 4. № 2286.

${ }^{5}$ См.: Высочайше утвержденное мнение Государственного Совета «О воспрещении ночной работы несовершеннолетним и женщинам на фабриках, заводах и мануфактурах» от 3 июня 1885 года. ПС3. III. Т. 5. № 3013.

${ }^{6}$ См.: Ташбекова И.Ю. Правовое регулирование деятельности фабричной инспекции в России в конце XIX - начале XX вв.: дис. ... канд. юрид. наук. М., 2006. С. 70.
} 
DOI: $10.7256 / 1811-9018.2015 .3 .9245$

При цитировании этой статьи сноска на dоі обязательна

\section{Право и политика $3(183) \cdot 2015$}

В 1886 г. под влиянием Морозовской стачки был принят главный нормативный акт, регулировавший трудовые отношения в дореволюционной России, и принятие которого ознаменовало возникновение новой отрасли права - трудового права. С.С. Коровникова, в частности, обращает внимание на то, что Закон от 3 июня 1886 г. «Об утверждении проекта Правил о надзоре за заведениями фабричной промышленности и о взаимных отношениях фабрикантов и рабочих и об увеличении числа чинов фабричной инспекции» ${ }^{7}$ незаслуженно обделен вниманием ученых ${ }^{8}$. Следует разделить указанный вывод С.С. Коровниковой, поскольку упомянутый закон подытожил многолетние усилия по принятию единого законодательного акта о труде, способного распространять свое действие на заведения фабричной промышленности, и от подчинения которому «в случаях действительной надобности» освобождались незначительные фабрики и заводы. Как уточняет В.И. Миронов, с появлением названного Закона стало возможным выделять самостоятельный предмет и метод трудового права: «предметом новой отрасли стали отношения по найму рабочей силы и использованию ее в процессе труда. Метод трудового права заключался в том, что условия трудовой деятельности определялись путем заключения индивидуального договора найма с выдачей расчетной книжки, а также посредством утверждения правил внутреннего трудового распорядка»?.

Таким образом, напряженная социально-политическая обстановка в стране решающим образом сказалась на качестве правового оформления отношений рабочего и предприятия, вследствие чего претерпел кардинальные изменения и приобрел цивилизованные черты сам характер и форма таких отношений. Не случайно предпринимаются попытки ${ }^{10}$ нормы Закона 1886 г. в зависимости от их содержания объединить в различные группы. Можно согласиться с мнением С.С. Коровниковой, по которому выделяют следующие группы норм: нормативное регулирование найма, заключение договора найма, заработная плата (размер,

\footnotetext{
${ }^{7}$ Высочайше утвержденное мнение Государственного Совета «Об утверждении проекта Правил о надзоре за заведениями фабричной промышленности и о взаимных отношениях фабрикантов и рабочих и об увеличении числа чинов фабричной инспекции» от 3 июня 1886 года. ПСЗ. III. Т. 6. № 3769.

${ }^{8}$ См.: Коровникова С.C. Нормативное установление содержания трудовых правоотношений в XIX веке // Социальное и пенсионное право. 2006. № 2. С. 39.

${ }^{9}$ Миронов В.И. Трудовое право: учебник для вузов. СПб.: Питер, 2009. С. 17.

${ }^{10}$ См.: Коровникова С.C. Нормативное установление содержания трудовых правоотношений в XIX веке. С. 39.
}

сроки выплаты и вычеты), прекращение и расторжение договора найма. Однако, если брать за основу структуру современного источника трудового права России ${ }^{11}$, представляется возможным сгруппировать действовавшие на тот момент нормы о труде следующим образом:

- общие положения, включающие в себя:

нормативное регулирование найма. Так, согласно ст. 1 закона 1886 г. наем рабочих совершался на основании общих постановлений о личном найме, а наем малолетних - на основании особо изданных на сей предмет правилами;

стороны, основание возникновения трудовых отношений, права и обязанности рабочего, заводского или фабричного управления, которые вытекают из положений статей Закона;

- договор о найме рабочих. Институт договора найма, в свою очередь, объединял нормы, которые регулировали:

общие положения договора найма (стороны, содержание и срок договора), заключение договора найма (документы, предъявляемые при заключении договора; оформление найма на работу; форма договора найма). Так, договор о найме рабочих подлежал заключению путем выдачи рабочим расчетных книжек, в которых обозначались условия найма, а также отмечались все производимые с ними расчеты и взимаемые с них вычеты (ст. 7). Расчетная книжка хранилась у рабочего и передавалась им в контору предприятия для внесения необходимых в нее записей (ст. 8). При найме заводское или фабричное управление было обязано требовать от рабочих предъявления вида на жительство (паспорта) (ст. 2). Наем рабочих производился: а) на определенный срок; б) на срок неопределенный; в) на время выполнения какой-либо работы (ст. 9). Уже сейчас мы можем указать на наличие сходных норм в ныне действующем Трудовом кодексе РФ;

изменение договора найма (ст. 11) - до окончания заключенного с рабочими срочного договора или без предупреждения за две недели рабочих, нанятых на неопределенный срок, запрещалось изменять определенные условия договора, как то: размер и основания для исчисления заработной платы, количество рабочих дней в неделю или рабочих часов в сутки и т. п. Равным образом и рабочие были не вправе до окончания срока договора требовать каких-либо изменений в его условиях; прекращение договора найма (ст.ст. 13, 19-21 Закона): по взаимному соглашению сторон (п. а ст. 19);

\footnotetext{
${ }^{11}$ Трудовой кодекс Российской Федерации: Федеральный закон от 30 декабря 2001 г. // Собрание законодательства Российской Федерации. 2002. № 1 (ч. 1). Ст. 3.
} 
по истечении срока найма или по окончании той работы, исполнением которой был обусловлен срок найма (п.п. б-в ст. 19);

в связи с расторжением договора найма по инициативе рабочего или предприятия, в частности, по истечении двух недель со дня заявления одной из сторон о желании расторгнуть договор, если он был заключен на неопределенный срок (п. г ст. 19);

в связи с расторжением договора найма по инициативе заведующего фабрикой или заводом (ст. 20 Закона): вследствие неявки рабочего на работу более трех дней подряд без уважительных причин (п. а), вследствие привлечения рабочего к следствию и суду по обвинению в преступлении, влекущем за собой наказание не ниже заключения в тюрьму (п. б), вследствие дерзости или дурного поведения рабочего, если оно угрожает имущественным интересам фабрики или личной безопасности лиц из состава фабричного управления (п. в), вследствие обнаружения у рабочего заразной болезни (п. г);

в связи с расторжением договора найма по инициативе рабочего (ст. 21 Закона): вследствие побоев, тяжких оскорблений и вообще дурного обращения со стороны хозяина, его семейства или лиц, осуществляющих надзор за рабочими (п. а), вследствие нарушения условий по снабжению рабочих пищей и помещением (п. б), вследствие работы, разрушительно действующей на здоровье рабочего (п. в), вследствие смерти или обязательного поступления на военную службу одного из членов семьи рабочего (п. г). Кроме того, рабочий, не получивший в срок причитающуюся ему плату, имел право требовать в судебном порядке расторжения заключенного с ним договора (ст. 13 Закона);

в случае высылки рабочего по распоряжению властей или назначения ему наказания в виде заключения на срок, делающий исполнение договора невозможным (п. д ст. 19), в случае поступления рабочего на обязательную военную или общественную службу (п. е ст. 19), в случае отказа рабочему в продлении срочного вида на жительство (п. ж ст. 19), в случае приостановления на продолжительное время работ на фабрике или заводе вследствие пожара, наводнения, взрыва паровика и т. п. несчастного случая (п. з ст. 19). Указанные обстоятельства, по которым подлежал прекращению договор найма, можно обозначить как обстоятельства, не зависящие от воли сторон (см. ст. 83 ТК РФ);

- оплата труда: общие положения (гарантии по оплате труда рабочих, форма оплаты труда) и заработная плата (размер, порядок и сроки выплаты; ограничение удержаний из зарплаты и их размера). Закон 1886 г. предусматривал выплату зарплаты рабочим не реже одного раза в месяц, если наем подразумевался на срок более месяца, и не реже двух раз в месяц - при найме рабочих на неопределенный срок (ст. 12). Следует заметить, что уже на тот момент законом устанавливались определенные государственные гарантии по оплате труда рабочих. В частности, государством провозглашалась неизменность установленной заработной платы в случае заключения срочного договора найма, а если наем рабочих осуществлялся на срок неопределенный - запрещалось понижать заработную плату без соответствующего предупреждения рабочих за две недели (ст. 11). К государственной гарантии по оплате труда рабочих следует отнести и ограничение оплаты труда в натуральной форме: запрещалась расплата с рабочими (вместо денег) купонами, условными знаками, хлебом, товаром и иными предметами (ст. 14). В систему государственных гарантий по оплате труда включалось также ограничение перечня оснований и размеров удержаний из заработной платы рабочих предприятием: в соответствии со ст. 15 Закона при выплате заработной платы не разрешалось удерживать средства на уплату долгов рабочих, к числу которых, однако, не относилось погашение задолженности за пользование фабричной лавкой; при предъявлении исполнительного листа с рабочего при каждой выплате зарплаты могло быть удержано не более $1 / 3$ причитающейся ему суммы, если он холост, и не более $1 / 4$, если он женат или вдов, но имеет детей; запрещалось взимать проценты за деньги, выданные авансом, и вознаграждение за поручительство по денежным обязательствам рабочих (ст. 16); запрещалось взимание с рабочих платы за врачебную помощь, за освещение мастерских и за пользование в процессе труда на фабрике орудиями производства (ст. 17). Как видим, некоторые современные государственные гарантии по оплате труда работников (ст. 130 ТК РФ) берут свое начало с законодательного регулирования труда в XIX веке;

- внутренний распорядок и дисциплина труда - заводское или фабричное управление составляло и вывешивало во всех мастерских обязательные для рабочих правила внутреннего распорядка (ст. 18). За виновное поведение рабочего, т.е. за отсутствие без уважительных причин на работе более трех дней подряд, дерзость или дурное поведение, заведующий фабрикой или заводом имел право расторгнуть с ним договор найма (ст. 20). Таким образом, в отличие от российского трудового законодательства имперское законодательство о труде знало лишь такой вид дисциплинарного взыскания, как увольнение;

- материальная ответственность фабриканта перед рабочим (основания и размер) - в случае задержки 
DOI: $10.7256 / 1811-9018.2015 .3 .9245$

При цитировании этой статьи сноска на доі обязательна

\section{Право и политика $3(183) \cdot 2015$}

выплаты заработной платы рабочий в течение трех месяцев имел право на предъявления иска, по которому в случае признания его требования уважительным в его пользу присуждалось сверх должной ему суммы особое вознаграждение в размере, не превышающем при срочном договоре двухмесячного его заработка, а при договоре, заключенном на неопределенный срок, - двухнедельного заработка (ст. 13);

- защита трудовых прав, рассмотрение трудовых споров в суде, виды ответственности за нарушение Закона. Так, к способам защиты трудовых прав относились: контроль исполнения закона фабричной инспекцией; судебная защита. В судах рассматривались трудовые споры по заявлению работника об обжаловании расторжения с ним договора по инициативе заведующего фабрикой или заводом, в результате чего могло быть вынесено постановление о вознаграждении рабочего за понесенные им убытки (примечание к ст. 20) и др. Анализ положений Закона показывает, что лица, виновные в нарушении норм права в сфере труда, могли привлекаться к дисциплинарной, материальной и уголовной ответственности. В этом смысле возможность привлечения фабричного или заводского рабочего к уголовной ответственности «за самовольный отказ от работы до истечения срока найма» означало отставание в качестве правового регулирования наемного труда, поскольку свобода физического труда должна опираться на запрет принуждения к вступлению в какое-либо объединение или пребыванию в нем.

Мы видим, что новеллами Закона от 3 июня 1886 г. явилось установление сроков выплаты зарплаты, запрета оплаты труда в недежной форме, а также развернутого перечня оснований прекращения и расторжения договора о найме рабочих. С другой стороны, содержание данного законодательного акта могло бы быть более высокого качества, если бы в законе были воспроизведены отдельные положения, касающиеся временной нетрудоспособности или гибели рабочего и др., появившиеся в законодательстве о регулировании наемного труда в связи с проведением крестьянской реформы 1861 г.

Кроме того, содержание статьи 22 исследуемого нормативного правового акта наводит нас на мысль, что качество правового регулирования отношений найма труда на частных предприятиях было на порядок выше, нежели на государственных предприятиях. Как говорится в данной норме, «в местностях, отличающихся значительным развитием фабрично-заводской промышленности, заведения этой промышленности, за исключением принадлежащих казне или правительственным установлениям, а также частных горных за- водов и промыслов, подчиняются, сверх постановлений статей 1-21, действию особых Правил о надзоре за заведениями фабричной промышленности и о взаимных отношениях фабрикантов и рабочих». Отсюда следует, что трудовые отношения на частных промышленных заведениях более детально и, следовательно, более качественно регулировались законодателем.

Отметим, что Правила в отличие от Закона устанавливали:

- срок выдачи рабочему расчетной книжки, который не мог составлять более семи дней с момента допуска его к работе на фабрике (п. 21); срок возврата рабочему расчетной книжки, который не мог превышать одной недели со дня представления расчетной книжки в контору фабрики или завода для внесения в нее необходимых записей (п. 25); материальную ответственность заведующего фабрикой или заводом за «держание рабочего без расчетной книжки» и за неправильное ее ведение (п. 40);

- содержание расчетной книжки, в которую включались: ФИО или прозвище рабочего; срок найма и вида на жительство; размер зарплаты, основания ее исчисления и сроки платежей; размер платы за пользование устроенными при фабрике или заводе квартирами, баней и т. п.; проч. условия найма, которые договаривающиеся стороны сочтут нужным внести в книжку; записи заработка, с указанием количества наложенных на рабочего взысканий и поводов к их наложению; извлечение из постановлений закона и правил внутреннего распорядка, определяющих права, обязанности и ответственность рабочих (п. 24);

- содержание правил внутреннего распорядка на фабриках, которые должны были включать в себя (п. 29): а) расписание (отдельное для взрослых и малолетних) часов начала и окончания работ, количество и продолжительность перерывов в работе для отдыха, завтрака и обеда, а также времени окончания работ перед воскресными и праздничными днями; б) расписание праздников, в которые работать не полагается; в) порядок и продолжительность отлучек с работы, а для рабочих, живущих в заводских или фабричных помещениях, - из этих помещений; г) условия пользования устроенными для рабочих при фабрике квартирами, банями и т. п.; д) указание времени чистки машин и аппаратов, а также уборки мастерских, если по условиям найма эти обязанности лежат на рабочих; е) определение обязанностей рабочих по соблюдению порядка и благочиния на фабрике; ж) требования предосторожности при обращении с машинами, огнем и т. п. Разработанные на фабриках правила внутрен- 
него трудового распорядка подлежали утверждению фабричным инспектором.

Доказательством того, что Правила в сравнении с Законом являлись более качественным нормативным правовым актом о труде, служит также то, что они в некоторой мере регламентировали взимание штрафов, определяя их основания и размер, устанавливали порядок определения взыскиваемого с рабочего ущерба, причиненного работодателю. В частности, никакие денежные взыскания не могли быть наложены на рабочих по другим поводам, кроме как: за неисправную работу, за прогул и за нарушение порядка (п. 30).

Так, за причиненный ущерб (производство по небрежности недоброкачественных изделий, порчу орудий производства) рабочий должен был нести материальную ответственность в пределах стоимости неисправности (п. 31).

Взыскание за прогул, т.е. неявку на работу в течение не менее половины рабочего дня, налагалось с учетом размера заработной платы и количества прогульного времени, но в размере, не превышающем суммы трехдневного заработка рабочего. Заработная плата за время прогула рабочему не выплачивалась. Для рабочих со сдельной оплатой труда взыскание за прогул определялось в размере не свыше одного рубля за прогульный день и не свыше трех рублей в общей сложности (п. 32). Взыскание за прогул, однако, не предусматривалось, если неявка на работу происходила вследствие лишения рабочего свободы, разорения от несчастного случая, пожара, разлива реки, болезни, лишающей возможности выйти из дома, смерти или болезни родителей, мужа, жены и детей. То есть ответственность рабочего за прогул наступала лишь в случае виновного нарушения трудовой дисциплины, что можно рассматривать в качестве одной из мер совершенствования действовавшего законодательства о труде.

Нарушением порядка на фабрике признавалось: а) несвоевременная явка на работу или самовольная отлучка с нее; б) несоблюдение в заводских или фабричных помещениях правил осторожности при обращении с огнем; в) несоблюдение в этих же помещениях чистоты и опрятности; г) нарушение тишины при работах шумом, криком, бранью, ссорой или дракой; д) непослушание; е) приход на работу в пьяном виде; ж) устройство игр на деньги. Взыскание за отдельное нарушение порядка не могло превышать одного рубля (п. 33).

Ко всему этому ограничивался общий размер взысканий. Так, взыскания, налагаемые за неисправную работу, за прогул и за нарушение порядка, в общей сложности, не должны были превышать «одной трети заработка, действительно причитающегося рабочему к установленному сроку расплаты» (п. 35).
Денежное взыскание, наложенное фабрикой на рабочего, записывалось в расчетную книжку не позднее трех дней со дня его наложения с указанием повода и размера взыскания. Все взыскания записывались, кроме того, в особо заведенную на фабрике или заводе шнуровую книгу, которая предъявлялась фабричным инспекторам по первому их требованию. При этом право рабочих на защиту своих трудовых прав и свобод ограничивалось тем, что распоряжения о наложении на рабочих взысканий обжалованию не подлежали. Однако, если чинами фабричной инспекции обнаруживалось из заявлений, сделанных рабочими, несоответствующее требованиям закона наложение на них взысканий, то заведующий фабрикой привлекался к ответственности. Более того, государство стремилось устранить и саму заинтересованность заведующего фабрикой или заводом в наложении взысканий на рабочих, предусмотрительно указав, чтобы все взыскания с рабочих обращались на составление «особого при каждой фабрике капитала», который мог быть употребляем с разрешения инспекции только на удовлетворение нужд самих рабочих (п. 39). По нашему мнению, рассмотренные правовые нормы о труде служили определенным компромиссом в отношениях рабочего и предприятия, что значительно увеличивало шансы на дальнейшее развитие качества фабричного законодательства.

На основе всего вышесказанного можно прийти к выводу, что принятие Закона от 3 июня 1886 г. ознаменовало собой не только появление самостоятельного предмета и метода трудового права, но и образование системы отрасли трудового права в целом, подтверждением чему служило наличие оснований для классификации трудовых норм внутри данной отрасли, а также структура соответствующих общественных отношений.

Обстоятельством, ухудшающим качество трудового законодательства в этот период, являлось то, что сохранение и развитие достигнутого его уровня зависели, прежде всего, от действия экономического фактора, настроений рабочих, а также самого желания предпринимателей, поскольку в первое время ряд законоположений о труде не содержал правовых механизмов, обеспечивающих их действие (например, в первое время полномочия фабричных инспекторов не были с необходимой четкостью установлены). Недостатки в развитии качества правового регулирования социально-трудовых отношений проявились и в том, что ограничения в применении труда женщин и подростков затрагивали на первых порах лишь отдельные отрасли промышленности. Однако проявление объективного и субъективного факторов, в конце концов, отрицательно сказалось на состоянии качества фабричного законодательства и привело к утрате некото- 
DOI: $10.7256 / 1811-9018.2015 .3 .9245$

При цитировании этой статьи сноска на dоі обязательна

\section{Право и политика $3(183) \cdot 2015$}

рых завоеванных ценностей. Так, например, Законом от 24 апреля 1890 г. «Об изменении постановлений о работе малолетних, подростков и лиц женского пола....» ${ }^{12}$ работа малолетних в возрасте от 12 до 15 лет на фабрике, заводе и мануфактуре в случаях, когда по роду производства это оказывалось необходимым, могла продолжаться 6 часов подряд. Однако общая продолжительность их работы не могла превышать 6 часов в сутки (ст. 1). В тех промышленных заведениях, в которых была введена 18-тичасовая непрерывная дневная работа с двумя сменами, малолетние в возрасте 12-15 лет могли привлекаться к работе в течение 9 часов в сутки, причем их работа не должна была продолжаться более 4,5 часов подряд (ст. 6). Другим свидетельством ухудшения качества правовой регламентации социально-трудовых отношений малолетних служило то, что стало допускаться привлечение их к работе в ночное время и с разрешения Главного фабричного инспектора-в воскресные и высокоторжественные дни (ст.ст. 2, 3 и др.).

Законом 1897 г. был несколько ограничен рабочий день для фабричных рабочих (вместо 14-16 ч. он стал равен 11-12 ч.). В 1860 и 1870 гг. на артиллерийских заводах и предприятиях морского ведомства был установлен 10-часовой рабочий день.

Таким образом, затянувшееся формирование рабочего класса привело к запоздалому возникновению трудового законодательства России. Только с ростом в конце XIX века активного недовольства рабочих условиями труда государство стало уделять особое внимание проблемам качества нормативного правового регулирования общественно-трудовых отношений.

\section{Библиография:}

1. Валетов Т.Я. Фабричное законодательство в России до Октябрьской революции. - URL: http://www.hist.msu.ru (дата обращения: 29.07.2013).

2. Высочайше утвержденное мнение Государственного Совета «О малолетних, работающих на заводах, фабриках и мануфактурах» от 1 июня 1882 г. - ПСЗ. ІІІ. - Т. 2. - № 931.

3. Высочайше утвержденное мнение Государственного Совета «О взысканиях за нарушения постановлений о работе малолетних на заводах, фабриках, мануфактурах и в ремесленных заведениях» от 5 июня 1884 г. - ПСЗ. III. - Т. 4. - № 2286.

4. Высочайше утвержденное мнение Государственного Совета «О воспрещении ночной работы несовершеннолетним и женщинам на фабриках, заводах и мануфактурах» от 3 июня 1885 г. - ПСЗ. III. - Т. 5. - № 3013.

5. Высочайше утвержденное мнение Государственного Совета «Об утверждении проекта Правил о надзоре за заведениями фабричной промышленности и о взаимных отношениях фабрикантов и рабочих и об увеличении числа чинов фабричной инспекции» от 3 июня 1886 г. - ПСЗ. ІІІ. - Т. 6. - № 3769.

6. Коровникова С.С. Нормативное установление содержания трудовых правоотношений в ХІХ веке // Социальное и пенсионное право. - 2006. - № 2. - С. 38-42.

7. Миронов В.И. Трудовое право: учебник для вузов. - СПб.: Питер, 2009. - 866 с.

8. Ташбекова И.Ю. Государственное регулирование труда несовершеннолетних и женщин России в конце XIX века // Черные дыры в российском законодательстве. - 2008. - № 3. - С. 269-271.

9. Ташбекова И.Ю. Правовое регулирование деятельности фабричной инспекции в России в конце XIX - начале XX вв.: дис. ... канд. юрид. наук. - М., 2006. - 176 с.

10. Трудовой кодекс Российской Федерации: Федеральный закон от 30 декабря 2001 г. // Собрание законодательства Российской Федерации. - 2002. - № 1 (ч. 1). - Ст. 3.

\section{References (transliterated):}

1. Valetov T.Ya. Fabrichnoe zakonodatel'stvo v Rossii do Oktyabr'skoi revolyutsii. - URL: http://www.hist.msu.ru (data obrashcheniya: 29.07.2013).

2. Korovnikova S.S. Normativnoe ustanovlenie soderzhaniya trudovykh pravootnoshenii v XIX veke // Sotsial'noe i pensionnoe pravo. - 2006. - № 2. - S. 38-42.

3. Mironov V.I. Trudovoe pravo: uchebnik dlya vuzov. - SPb.: Piter, 2009. - 866 s.

4. Tashbekova I.Yu. Gosudarstvennoe regulirovanie truda nesovershennoletnikh i zhenshchin Rossii v kontse XIX veka // Chernye dyry v rossiiskom zakonodatel’stve. - 2008. - № 3. - S. 269-271.

5. Tashbekova I.Yu. Pravovoe regulirovanie deyatel'nosti fabrichnoi inspektsii v Rossii v kontse XIX - nachale XX vv.: dis. ... kand. yurid. nauk. - M., 2006. - $176 \mathrm{~s}$.

\footnotetext{
${ }^{12}$ Высочайше утвержденное мнение Государственного Совета «Об изменении постановлений о работе малолетних, подростков и лиц женского пола на фабриках, заводах и мануфактурах и о распространении правил о работе и обучении малолетних на ремесленные заведения» от 24 апреля 1890 года. ПСЗ. III. Т. 10. № 6742.
} 